\title{
De la política de la imaginación a la política Imaginal ${ }^{1}$ From Politics of Imagination to Imaginals Politics
}

\section{Chiara Bottici}

Chiara Bottici es profesora e investigadora de la New School for Social Research, Estados Unidos.

E-mail: botticic@newschool.edu

\section{resumen}

El presente artículo se propone reevaluar el vínculo conceptual entre la política y nuestra capacidad de crear imágenes. A pesar de que se ha escrito mucho en torno a la política de la imaginación, no hay muchos trabajos que evalúen críticamente el vínculo conceptual entre estos dos conceptos de una forma sistemática. Este escrito propone el concepto de Imaginal, entendido como aquello hecho por imágenes, para trascender el impasse actual de la oposición, por una parte, entre teorías de la imaginación como una facultad individual, y por otra, teoría de lo imaginario como un contexto social. A raíz de lo dicho, se fundamentará que la teoría de lo imaginal es el instrumento teórico que más se adapta para comprender la relación conceptual entre la política y nuestra capacidad de producir imágenes. Por último, este análisis se aplica a la política contemporánea y demuestra su capacidad de esclarecer muchas de sus paradojas, incluida aquella de un mundo de la política lleno de imágenes, pero privado de imaginación.

\section{palabras clave}

político / política / imaginal / imaginación / imaginario

\section{summary}

This article intends to reconsider the conceptual link between politics and our faculty to create images. Despite the fact that much has been written about the politics of the imagination, there are not many works that critically evaluate the conceptual link between these two concepts in a systematic way. The present article proposes the concept of imaginal, understood as what is made of images, to transcend the existing impasse of the opposition between theories of imagination as an individual capacity, on the one hand, and theories of the imaginary as a social context, on the other. The concept of imaginal is the theoretical apparatus most adapted to capture the nature of the conceptual link between politics and our capacity to produce images. Finally this analysis is applied to contemporary politics and it is shown to be able to bring light to many of its paradoxes, included that of a political world full of images, but deprived of imagination keywords

political / politics / imaginal / imagination / imaginary 
Usualmente oímos a la gente decir que nuestros políticos carecen de imaginación. En épocas de la gobernanza global, cunado la política es reducida a mera administración, parece existir muy poco espacio para el libre desarrollo de la imaginación. Sin embargo, si consideramos la espectacularización de la política que aparece en nuestras pantallas diariamente, no podemos sino percibir un exceso de imaginación. ¿Cómo podemos explicar la paradoja de un eclipse de la imaginación que va paralelo con su hipertrofia? En orden de lidiar con esta paradoja, necesitamos repensar el vínculo entre la política y nuestra propia capacidad de imaginar.

En orden de hacer esto, en primer lugar comenzaré con una discusión del concepto de imaginación donde señalaré las omisiones de una aproximación a nuestro problema desde una teoría de la imaginación entendida como una facultad individual. El concepto de imaginación, como ha sido desarrollado en la tradición de la filosofía moderna, está imbuido de la presuposición de una problemática filosófica del sujeto y el problema sin solución relacionado de la realidad de la imaginación. El pasaje de una teoría de la imaginación política a una teoría del imaginario político, es decir, de una aproximación orientada subjetivamente a otra orientada contextualmente, como es ilustrada en una comparación de Arendt con Castoriadis también genera tensiones sin solución: si partimos de la idea de imaginación como una facultad individual, el problema es cómo explicar el impacto en el contexto social, mientras que si comenzamos desde una teoría del imaginario político el problema es como dar cuenta de la libre imaginación de los individuos (1) De aquí la necesidad de movernos hacia una teoría de lo imaginal. Esta última se mostrará como la mejor herramienta para conceptualizar la relación de la política y nuestra capacidad para imaginar (2), así también como para capturar el sentido de sus transformaciones contemporáneas (3).

\section{(1) Imaginación e imaginario de una facultad individual al contexto social}

Si uno mira en la genealogía del concepto de imaginación, no es difícil de percibir dos áreas semánticas considerablemente diferentes. ${ }^{2}$ La primera, la cual vuelve atrás al término griego phantasia, está asociada con la producción de imágenes en el sentido más general (phantasmata). Desde esta visión, la imaginación juega un rol importante tanto en la acción como en la cognición. Aristóteles, por ejemplo, define la phantasia como "un movimiento (kynesis) producido por la sensación en acto" que deriva de la raíz de la palabra luz (phaos), argumentado que sin luz es imposible la visión (De Anima, 429a). Phantasia es aquí reconocida con un rol importante para la formación de una imagen unitaria de objetos a partir de un conjunto de datos que de otro modo no estaría relacionado (ver particularmente De Anima, 428b 18-30). Es solamente gracias a esta facultad que una colección de formas, colores, movimientos, etc. es percibido como una mesa. Aristóteles, también reconoce que ninguna acción es posible sin phantasia porque la phantasia está en la base del apetito, que es una forma de movimiento (De Anima, 433b 29). ${ }^{3}$

Es en la época moderna que el concepto de imaginación comienza a estar asociado sistemáticamente con un área semántica bastante diferente. Lejos de ser una 
fuente de luz, la imaginación es ahora vista como una fuente de oscuridad, de perturbación del trabajo metódico de la razón. Una división es establecida entre el conocimiento por una parte, que está garantizado por la ilustración de la pura razón, y la imaginación como la facultad de producir toda clase de matrimonios y divorcios ilegales. Francis Bacon define la imaginación como la facultad que "usualmente excede la medida de la naturaleza, uniendo cosas placenteras que en la naturaleza nunca estarían juntas, e introduciendo cosas las cuales en la naturaleza nunca han llegado a pasar" (Bacon 1986, II, 1: 292; 1963 II, 1: 494). ${ }^{4} \mathrm{Si}$ la imaginación no tiene ningún rol en la cognición, aún puede ofrecer algo a los seres humanos: lo poético. La imaginación, junto con la memoria y la razón, es una de las tres facultades de la mente, las cuales corresponden a las tres grandes divisiones del saber humano: poesía, historia y filosofía (Bacon 1986, II, 1: 292).

Tal vez, en ningún otro autor la crítica a la imaginación es tan clara como en Pascal. En su fragmento sobre la imaginación, Pascal describe esta facultad como una fuente de error y falsedad (maîtresse d'erreur et fausseté), como una poderosa enemiga de la razón la cual puede controlar, y algunas veces, hasta dominar completamente (ver fragmento 44/82, Pascal 1963: 504). Si la razón nunca puede vencer completamente a la imaginación lo contrario es usualmente una regla. Esto último obedece a la naturaleza corrompida de los seres humanos, quienes, como consecuencia del pecado original están "llenos de errores naturales, los cuales no pueden ser eliminados sin la gracia divina" (ibi: 505). ${ }^{5}$ La imaginación, más que otra facultad humana, es el signo de la irremediable naturaleza corrupta de los seres humanos, del hecho de que ellos no siempre pueden seguir las otras dos fuentes de verdad que son: la razón y los sentidos. ${ }^{6}$

Este pasaje de una mirada positiva de la imaginación asociada con la esfera de la luz, a una negativa que ve en ella un signo del lado oscuro de la naturaleza humana, implicó una quiebra semántica sorprendente. El resultado de las grandes críticas del siglo XVII al concepto de imaginación es el hecho de que para el siglo XVIII el término "phantasia" se ha movido hacia la esfera de lo irreal-como aún es el caso del correspondiente término inglés "fantasy" ${ }^{7}$ Los intérpretes pueden discutir la connotación más o menos positiva del término "imaginación", pero generalmente consensúan en posicionar "fantasy" en la esfera de lo irreal y la recientemente constituida esfera de lo estético (Friese 2001: 7197; Vattimo 1999b: 529).

Ambas visiones de la imaginación, la positiva y la negativa, acuerdan en un punto fundamental: la imaginación es una facultad individual. Las controversias pueden surgir en cuanto a su evaluación, pero la mayoría de los filósofos modernos acuerdan en situar a la imaginación al lado de la razón, el intelecto y otras facultades humanas individuales. Aun el romanticismo, el cual procura revalorizar el rol central de la imaginación, al negar la primacía del intelecto para la consecución del conocimiento, comparte ampliamente esta premisa. Los pensadores románticos como Novalis, Schlegel y Fichte enfatizan el lado productivo de la imaginación, argumentado que esta facultad puede sobreponerse al carácter abstracto y mecanicista del intelecto. ${ }^{8}$ Sin embargo, semejante ensayo se presenta más como una restauración de lo que había sido criticado por la ilustración, que un cuestiona- 
miento radical de las premisas ilustradas en sí. Como he argumentado en otro sitio, esto obedece a que el romanticismo permanece completamente dentro, y algunas veces, hasta hipertrofia la metafísica del sujeto sostenida por la ilustración. Ya sea el absolutismo de un ego que abarca el mundo exterior en sí mismo, o la metafísica de un espíritu nacional (Volksgeist), el sujeto moderno es, en todos estos casos, reinterpretado, expandido, hipertrofiado, pero no cuestionado radicalmente. ${ }^{9}$

La tarea de este ensayo es subrayar la necesidad de ir un paso más lejos, que consiste en reivindicar el poder de nuestra capacidad para imaginar, y al mismo tiempo evitar la trampa de una filosofía del sujeto. Nosotros no somos puros sujetos que simplemente contemplamos un mundo que nos es dado, pero tampoco somos el sujeto romántico que encapsula al mundo dentro de su conciencia. Somos algo entre estos dos. El problema es comprender qué somos como seres "imaginantes".

Como ha sido observado, una gran parte de los trabajos filosóficos han procurado alejarse del concepto de razón encapsulado en la filosofía del sujeto,-como se ha distinguido, terminológicamente hablando, por el pasaje del término "razón" al, más orientado contextualmente, "racionalidad" (Arnason, 1994). Mientras una gran cantidad de trabajos se han realizado en torno al concepto de racionalidad y su posible contribución al proyecto de autonomía, nada similar se ha realizado en torno al concepto de imaginación. En comparación con la razón, la imaginación, ha quedado como un tópico marginal en los debates filosóficos recientes. No obstante, tal como el movimiento de la filosofía del sujeto a un nuevo énfasis en el contexto ha llevado de una teoría de la "razón" a una de la "racionalidad", también hemos presenciado un desarrollo paralelo de una teoría de la "imaginación" a una teoría del "imaginario".

Tanto el psicoanálisis como el estructuralismo han contribuido a este desarrollo, el primero con un nuevo énfasis en la complejidad de la vida psíquica y el último con una nueva atención a los productos de la imaginación. Mitos, fábulas, cuentos de hadas, rituales, prácticas totémicas, todos han sido analizado como parte del imaginario social. Solo debemos pensar en las contribuciones de Freud y Jung en esta dirección, o más recientemente, en el análisis estructuralista inspirado en Lévi-Strauss ${ }^{10}$, lo que ciertamente ha contribuido a una más profunda comprensión del concepto de imaginario. Tal vez el resultado más importante es el distanciamiento de una visión del yo como una mera suma de facultades separadas, visión que prevalece en la mayoría de los filósofos modernos, de Bacon a Kant.

Sin embargo, el riesgo de colocar mucho énfasis en el contexto es el reemplazo de un problemática de una metafísica del sujeto por una problemática equivalente de una metafísica del contexto. El punto es hallar un camino, que por una parte, mantenga el balance entre el sujeto y el contexto, y por otra, entre los diferentes sujetos y los diferentes contextos. Dos riesgos se deben evitar. El primero es la tentación de recomponer el contexto en un sujeto, allende que éste sea comprendido de una manera más compleja. Por ejemplo, esto puede suceder al considerar los diferentes productos del imaginario social como meros resultados de las características universales de la mente humana, sean los complejos universales (Freud) o 
las estructuras lingüísticas universales (Lévi-Strauss). El peligro aquí, es subsumir el contexto en una metafísica del sujeto que, más allá de ser comprendido de una forma más compleja (incluyendo tanto la vida consciente e inconsciente), es aún un sujeto concebido como separado de la realidad que él o ella enfrenta.

El segundo riesgo es recomponer el sujeto dentro del contexto, o los contextos en plural, como sucede, por ejemplo, en muchas concepciones que han sido inspiradas por el romanticismo o por la filosofía del lenguaje del segundo Wittgenstein, donde el sujeto es disuelto en una simple forma de vida auto-cerrada. Estos, como consecuencia, a menudo se ven como contextos recíprocamente incomunicables (Von Savigny, 1991; Coulter, 1999). El argumento básico aquí es que si el significado proviene del lenguaje, y si éste se encuentra básicamente encapsulado en formas de vida separadas una de otra, no hay comunicación posible entre ellas. ${ }^{11}$ El problema, sin embargo, es que esta visión reifica los contextos, como si fueran unidades auto-cerradas, y por lo tanto termina intercambiando el punto de vista de la filosofía del sujeto por una metafísica del contexto, esto es, una forma de solipsismo a larga escala.

El problema filosófico que emerge del pasaje de la teoría de la imaginación como una facultad individual a la del imaginario como un contexto social puede quizás ser ilustrada al comparar la aproximación de dos pensadores que enfatizan decisivamente el nexo entre nuestra capacidad de imaginar y la política, entendida de forma amplia: Hannah Arendt y Cornelius Castoriadis. Como veremos, este pasaje demuestra ser insuficiente, y sólo al movernos un paso más allá, hacia una teoría de lo imaginal, es que las ideas tanto de Arendt como de Castoriadis, se pueden recuperar para llegar a un acuerdo con las transformaciones contemporáneas.

Nuevamente, parte del problema se debe a la poca atención que los filósofos dedicaron al concepto de imaginación/imaginario a partir de su énfasis en el de razón/racionalidad. Quizás sea emblemático que una de las teorías filosóficas potencialmente más poderosas de la imaginación política permaneció no escrita. El proyecto de Hannah Arendt, en los últimos años de su vida, era el de una teoría del juicio basada en el concepto de imaginación, pero murió antes de poder haber completado el desarrollo de su teoría. En lugar de una teoría completa, que pudo haber representado la fruta más madura de la herencia fenomenológica, nos han quedado algunos fragmentos de una posible teoría. ${ }^{12}$ Tras recuperar la intuición de Kant, en particular como fue desarrollada en la primera edición de la Crítica de la razón pura $^{13}$, Arendt subraya el poder de la imaginación tanto para la acción como para la cognición. La imaginación es la facultad que media entre lo universal y lo particular, al proveer esquemas para la cognición y ejemplos para la acción (Arendt 1982: 72 y ss., 79-85). Como Kant ya había argumentado, para explicar cómo era posible que una serie de datos sensibles puedan ser reconocidos como un objeto unitario - una mesa- debemos poseer una imagen mental de cómo debe ser una mesa. Arendt argumenta:

"Esto puede ser concebido como una idea platónica o un esquema kantiano... Queda todavía otra posibilidad relacionada con los juicios no cognitivos: uno puede encontrar o pensar en una mesa que juzgue la mejor posible y tomarla como 
ejemplo de como las mesas deben realmente ser: la mesa ejemplar (ejemplo proviene de eximere, distinguir un particular). Este ejemplar es y sigue siendo un particular, que en su misma particularidad revela la generalidad que no podría determinarse de otro modo. El coraje es como Aquiles, etc." (Arendt 1982: 76-77). ${ }^{1415}$

No obstante, la imaginación, como Arendt argumenta en otro lugar, es también central en la vida humana, desde otro punto de vista. En tanto la facultad de hacer presente lo que está potencialmente ausente, se encuentra en la base misma de las posibilidades de la acción. Como señala al comienzo de "La mentira en política", una característica de la acción humana es que siempre comienza algo nuevo en el mundo -lo que no significa que comienza ex nihilo, sino que simplemente agrega algo. Esta capacidad de comenzar algo nuevo depende, a su vez, de nuestra capacidad de retirarnos mentalmente a nosotros mismos de donde estamos localizados físicamente e imaginar que las cosas podrían ser diferentes de lo que realmente son (Arendt, 1972: 5). Esta capacidad de cambiar hechos o de actuar depende, por lo tanto, fundamentalmente de la imaginación. Pero, como Arendt observa, de la misma facultad también depende la capacidad, tan común en política, de negar la verdad de los hechos (Arendt, 1972: 5). Aquí surge la ambivalencia de la imaginación, el hecho de que puede ser un medio para la emancipación y de crítica de lo dado, pero también de la sujeción a ello. Dicho de otra manera, la imaginación puede ser tanto una fuente de autonomía como de heteronomía.

Sin embargo, el filósofo que sistemáticamente más enfatizó la necesidad de repensar el concepto de imaginación en conexión con el proyecto de autonomía no es Arendt, sino Cornelius Castoriadis. Además, también ha contribuido al pasaje de una teoría de la imaginación (como aún es la desarrollada por Arendt) a una del imaginario. El razonamiento de Castoriadis es bastante sencillo: todos los actos, sin los cuales una sociedad no podría sobrevivir -labor, consumo, amor, guerra, etc.- son imposibles por fuera de una red simbólica, aun aquellos que no son ellos mismos directamente símbolos (Castoriadis, 1987: 117). Toda sociedad constantemente define y redefine sus necesidades, y ninguna sociedad puede sobrevivir por fuera de las significaciones imaginarias que constituye y que la constituyen a ella. La institución de la sociedad presupone la institución de significaciones imaginarias que deben, en principio, ser capaces de proveer sentido a todo lo que se presente: cualquier irrupción del caos en bruto puede ser tratada como un signo de algo y así interpretada. Aun los eventos que colisionan con las significaciones imaginarias dadas pueden ser sujetos de un procesamiento simbólico: las transgresiones de las reglas sociales se convierten en "enfermedades", las sociedades extranjeras se convierten en "salvajes", "extrañas" o incluso "impías" (Castoriadis, 1991).

Al mismo tiempo, una gran amenaza permanece en la sociedad instituida: su propia creatividad. El mérito del concepto de imaginario social radical de Castoriadis es señalar que el imaginario social instituyente es siempre al mismo tiempo instituido. Ninguna sociedad podría siquiera existir si los individuos creados por la sociedad misma no la crean a ella. La sociedad sólo puede existir concretamente por la encarnación e incorporación fragmentaria y complementaria de su institución y sus significados imaginarios en los individuos que viven, hablan y 
actúan en esa sociedad. La sociedad ateniense no es nada sin los atenienses, observa Castoriadis: sin ellos, es sólo los restos de un paisaje transformado, los restos de mármol y jarrones, inscripciones indescifrables y estatuas gastadas pescadas en el Mediterráneo. Pero los atenienses son atenienses sólo por medio del nomos de la polis. Es en esta relación entre, por una parte, una sociedad instituida -la cual trasciende infinitamente la totalidad de individuos que la componen, pero que en realidad sólo puede existir "realizada" en los individuos que produce- $y$, por otra parte, estos individuos que experimentan un tipo de relación sin precedentes que no puede ser pensada bajo la categoría del todo y sus partes, el conjunto y sus elementos y, menos aún, de lo universal y lo particular (Castoriadis, 1991: 145).

No obstante, Castoriadis parece contradecir esta visión cuando habla de la "absoluta escisión" entre los dos polos del imaginario social instituido e instituyente: lo histórico social por una parte, y lo que él llama la psique o la monada psíquica por otra (ver Castoriadis, 1987: 204 y ss.). Se dice que la psique es monádica porque es un "fluido puramente representacional/afectivo/intencional", indeterminado, y en principio indominable. Inspirándose en la teoría, pero también en su propia experiencia como psicoanalista, Castoriadis arguye que es sólo a través de un proceso de socialización siempre incompleto, violento y enérgico que se puede producir un individuo social. Esto sucede a través de un proceso de aprendizaje que comienza con el primer encuentro con el lenguaje (en primer lugar el lenguaje materno). A través de la socialización, la psique es forzada a renunciar a sus objetivos iniciales e invertir (cathect) en objetos, reglas y el mundo instituidos socialmente. Es a través de la internalización de los mundos y las significaciones imaginarias creadas por la sociedad que un "individuo", propiamente hablando, se crea a partir de un "monstruo que grita".

Como ha sido observado, la tesis de Castoriadis sobre el aislamiento monádico y la heterogeneidad fundamental entre la psique y la sociedad parece conducir a una muy problemática, y por lo tanto insostenible, oposición metafísica (Habermas, 1987: 327). Una vez que nos encontramos dentro del aislamiento monádico del inconsciente, se torna difícil explicar cómo la comunicación es siquiera factible en primer lugar (Whitebook, 1989). ${ }^{16}$ Sin embargo, como se observará, es posible recuperar las ideas de Castoriadis en torno al rol del imaginario social instituyente e instituido sin depender de tales supuestos metafísicos. En particular, aun dentro de una visión del yo inspirada en el psicoanálisis no hay necesidad de concebir la psique en términos de aislamiento monádico. Más bien, podría argumentarse que nuestro instinto básico cuando entramos al mundo es relacionarnos con el otro, en particular con la figura materna en busca de alimento. No somos seres monádicos que nos tornamos interdependiente a través de un violento proceso de socialización. Al contrario, somos desde un principio seres dependientes, a pesar de nuestros impulsos monádicos. ${ }^{17}$

Para resumir, el mérito de la teoría de Castoriadis es doble. En primer lugar, se distancia de la visión de la imaginación como representación de aquello que está ausente, la cual aún prevalece en Arendt. No es por casualidad que Castoriadis caracteriza su visión del imaginario como radical. El término radical 
debe ser comprendido tanto en el sentido político como filosófico. En el sentido político, se refiere a la necesidad de repensar la imaginación en relación con el proyecto de autonomía, el cual, como hemos comentado, es una preocupación crucial para Castoriadis. En un nivel general más filosófico, el término radical tiene la función de subrayar que, como mantenía Aristóteles, junto con una "phantasia" imitativa y reproductiva o combinatoria, también existe lo que podemos llamar una imaginación primaria. Esta consiste en la facultad de producir "imágenes en el sentido más amplio (formas, 'Bilder'), imágenes sin las cuales no habría ningún pensamiento en absoluto, y las cuales, por lo tanto, preceden todo pensamiento" (Castoriadis, 1994). Por lo tanto, la imaginación no implica la no existencia de los objetos de imaginación, aunque también podemos tener imágenes que no corresponden a nada en el mundo externo. La imaginación es anterior a la distinción entre "real" y "ficticio". En otras palabras, es por la existencia de la imaginación radical que la realidad existe para nosotros y, por lo tanto, uno podría agregar, existe tout court (Castoriadis, 1994). ${ }^{18}$

En segundo lugar, el mérito de Castoriadis es el de problematizar la visión de la imaginación como una facultad individual, centrándose sistemáticamente en el concepto de imaginario social. Esto último señala que no hay un sujeto, por un lado, y la realidad, por otro. Como ya hemos notado, el pasaje del concepto de Imaginación al de Imaginario refleja un cambio de una aproximación orientada al sujeto a una orientada al contexto (Arnason, 1994). El concepto de Imaginario Social de Castoriadis también tiene la función de subrayar la idea de que la definición de realidad en sí misma depende del imaginario social instituyente e instituido y no viceversa (Castoriadis, 1991: 147). El hecho de que la palabra "realidad" haya sido concebida de manera tan diferente muestra que todas las sociedades han constituido de algún modo su realidad. ${ }^{19}$ Para resumir, mientras que Arendt permaneció relacionando a la vez la idea de imaginación como una facultad individual y la idea de imaginación como una facultad que representa lo que está ausente, Castoriadis problematiza ambas ideas, argumentado que ninguna facultad existe por fuera de un contexto social y que la imaginación se da con anterioridad a cualquier distinción entre lo real y lo irreal.

Dicho de otra manera, la definición de lo "real" es el resultado de la dialéctica entre el lado instituido e instituyente del Imaginario social. Detrás de esta idea hay una visión compleja de la relación entre los individuos, que sólo pueden existir dentro de significaciones imaginarias, y el imaginario social, el cual sólo puede existir en y a través de los mismos individuos. Sin embargo, Castoriadis afirma que esta complejidad no puede ser reducida a las relaciones simples como las del todo y la parte, lo general y lo particular, las cuales estarían en desacuerdo con la idea de Castoriaidis de la completa heterogeneidad entre la psique monádica y la sociedad. Nuevamente, el problema es el de cómo concebir la relación entre el sujeto y el contexto.

Como hemos visto, el concepto de imaginación se sitúa dentro de la filosofía del sujeto, mientras que el de imaginario mantiene una distancia de esta visión. El peligro, no obstante, es caer en una metafísica de los contextos igualmente proble- 
mática. Parecería que no hay salida a esta dificultad: si se comienza con la "imaginación" concebida como una facultad individual, el problema es cómo concebir la relación entre la imaginación individual y el contexto social. Si se comienza con el concepto de imaginario social, entonces el problema es cómo reconciliarlo con la libre imaginación individual. El problema parece insoluble y la oposición metafísica entre la sociedad y la mónada psíquica de Castoriadis es un signo de que no hay una salida fácil.

\section{(2) Lo Imaginal y lo político}

Una primera dirección de investigación para hallar la salida del impasse filosófico descripto anteriormente es comenzar con un cuestionamiento radical del punto de inicio: "imaginación" como una facultad individual e "imaginario" como un producto social. Si concebimos a los seres humanos como el resultado siempre problemático de una tensión entre los dos polos, como seres igualmente dependientes e independientes, sociales y monádicos -como pienso que deberíamos hacer-, entonces necesitamos un nuevo concepto. Después del pasaje de la imaginación al imaginario necesitamos realizar un paso más y centrarnos en lo que podemos llamar lo "imaginal". Si la imaginación es una facultad individual y el imaginario un contexto social, imaginal es simplemente lo que está hecho de imágenes, un adjetivo que denota algo que puede ser producto tanto de una facultad individual como de un contexto social. Dicho de otra manera, es simplemente la característica de un producto que se encuentra entre los dos.

El término "imaginal" ha sido introducido en el debate filosófico actual (principalmente en Francia) por Henri Corbin, que lo recupera de la filosofía islámica. Aquí, el término latino mundus imaginalis, del árabe 'alam al-mithal, denota todo lo que se encuentra entre el mundo de las intuiciones intelectuales puras y el de la mera percepción de los sentidos (Corbin, 1979). Corbin, como otros luego de él, utiliza el concepto para propósitos específicos (recobrar la intuición de la filosofía islámica), pero para nosotros es suficiente notar que el concepto de imaginal apunta al hecho de que entre el puro intelecto y las formas de la sensibilidad, para usar la expresión kantiana, existe algo más, que también posee una función cognitiva y que no es posible relegar simplemente al ámbito de lo irreal y de lo ficticio.

El objetivo principal de Corbin y sus seguidore ${ }^{20}$ es el de distinguir entre "imaginal" (imaginal), como aquello que está hecho de imágenes, e imaginario (imaginaire), que en francés, la lengua de Corbin, significa lo que es puramente ficticio, irreal. La misma distinción sostiene el idioma inglés, donde lo "imaginal", de acuerdo con el Oxford English Dictionary, denota primariamente lo que pertenece a la imaginación o a las imágenes mentales, mientras "imaginario" significa primariamente lo que existe sólo en la fantasía y carece de existencia real, por lo tanto opuesto a lo "real", a lo "actual" (Simpson and Wiener, 1989, vol II: 668).

Para concluir con este punto, el concepto de imaginal apunta al hecho de que el contenido de nuestras imágenes no es necesariamente irreal, aunque éste también puede ser el caso (y aquí, como veremos, yace la ambivalencia de lo imaginal). "Imaginal" se opone en primer lugar a lo "imaginario" como un adjetivo que de- 
nota una característica de imágenes. A su vez, "imaginal" también se distingue de "imaginario" como sustantivo, porque lo que está compuesto simplemente de imágenes puede ser tanto un producto del imaginario social como de una facultad individual.

¿Cuál es la relación entre lo imaginal y lo político? ${ }^{21}$ Como mostraré aquí, es dentro de la perspectiva de una teoría de lo imaginal que también podemos recuperar algunos de los elementos postulados por Arendt y Castoriadis en cuanto al vínculo sistemático entre la política y nuestra capacidad de imaginar. Si entendemos política, en el sentido más amplio, como lo perteneciente a la polis, a las decisiones que conciernen al destino de la comunidad, la relación es bastante clara. En este sentido, la política coincide con lo público y por lo tanto también incluye todo lo que concierne a lo social y a lo político. ${ }^{22}$ La política así comprendida depende de lo imaginal, ya que es sólo imaginando lo público que éste existe. Esto es válido para grandes comunidades como los estados modernos, pero también para las pequeñas. Si las primeras son evidentemente seres "imaginales", porque es obvio que sólo imaginándolas es posible percibir el sentido de pertenencia con completos extraños, lo mismo ocurre para las últimas: aun en una pequeña comunidad, basada en relaciones cara a cara, hay una necesidad de imaginar una comunidad con el fin de hacer que exista más allá de una simple colección de individuos. Las comunidades existen porque imaginamos que existen. Lo que se ve reunido en el agora ateniense es un conjunto de cuerpo, no (aun) una polis. Digo seres imaginales, y no seres imaginados, para señalar que no son sólo el producto de acciones por parte de los individuos, sino también lo que da forma a la imaginación de los individuos. $^{23}$

Para sintetizar, lo político es imaginal porque depende de la posibilidad de imaginar la comunalidad, pero también, como veremos ahora retornando a Arendt, porque depende de nuestra capacidad de liberarnos de nuestras particularidades. En su lectura política de la noción kantiana de gusto, Arendt subraya precisamente este punto. Nuestra capacidad de formar imágenes es lo que media entre lo particular y lo universal en los juicios y, en consecuencia, es lo que nos permite tomar el punto de vista del otro. Como escribió en sus comentarios sobre la Crítica del Juicio de Kant: "Una comunidad amplia es la condición sine qua non del juicio correcto; el sentido comunitario permite ampliar la propia mentalidad...Los factores privados nos condicionan, la imaginación y la reflexión nos permiten liberarnos y conseguir aquella imparcialidad relativa que es la virtud propia del juicio" (Arendt, 1982: 73). ${ }^{24}$

En consecuencia, lo imaginal es lo que nos permite percibir el ser-en-común, pero también, al mismo tiempo, lo que lo hace existir. Si no podemos tomar el punto de vista de los otros, ponernos en sus zapatos, asumir una mentalidad amplia, entonces nada político lato sensu puede existir. Sin embargo, lo imaginal también es central para la política si la entendemos en su sentido más restringido como una actividad caracterizada por su recurso potencial de legitimar la coerción. ${ }^{25}$ El poder político es una forma específica de poder, donde el poder en general es la capacidad de hacer que alguien haga lo que de otra manera no haría. En este sentido, el poder político difiere de otras formas de poder precisamente porque puede recurrir 
a la coerción física legítima. Sin embargo, para ser percibido como legítimo, el poder político necesita tener sentido dentro de las significaciones imaginarias de una sociedad. Si fracasa, cesa de ser poder político y deviene mera violencia, fuerza física. Esta es, en última instancia, la razón por la que se apoya en lo imaginal.

Como Castoriadis también nota, el poder político (que él denomina a veces el "poder explícito") es esencial a toda sociedad. Esto es así, debido a que el infrapoder fundamental ejercido por la dimensión instituyente de la sociedad nunca puede tener un éxito completo en su intento de forjar sujetos obedientes. La dimensión instituida de lo socio-histórico siempre emergerá nuevamente, porque ninguna sociedad puede subsumir completamente a los individuos en sí misma. Esta es la razón por la cual, en la mirada de Castoriadis, hay siempre una dimensión de las instituciones sociales a cargo de esta función esencial: reestablecer el orden, asegurar la vida y la reproducción de la sociedad contra aquello que la pone en peligro (Castoriadis, 1991: 154).

Ya sea que este poder sea en principio necesario, como arguye Castoriadis, o no, es indudable que, en tanto exista, debe depender de lo imaginal. Para ponerlo en las palabras de Castoriadis: "debajo del monopolio de la violencia legítima yace el monopolio de la significación válida. El trono del amo de la significación se encuentra por encima del trono del amo de la violencia. La voz de las armas sólo comienza a ser escuchada en medio del colapso de la caída del edificio de instituciones. Y para que la violencia pueda intervenir es necesario que la palabra -el imperativo del poder existente- asiente su poder en los 'grupos de hombres armados' (Engels)" (Castoriadis, 1991: 155-6). ${ }^{26}$

Puede haber innumerables fuentes de legitimidad. Si tomamos, por ejemplo, la tipología weberiana de los fundamentos de legitimidad (tradición, fe, legislación), vemos que todos ellos dependen de una forma u otra de lo imaginal (Weber, 1978, vol. I: 36-38, 212 y ss.). En el caso del poder carismático, las personas obedecen las órdenes porque tienen fe en la sacralidad o la imagen heroica de la persona que lo ejerce. La imaginación es también crucial en el poder tradicional. Ninguna tradición puede ser respetada sin ser imaginada al mismo tiempo. ¿Qué es la tradición sino un ente imaginal? Finalmente, la imaginación es también crucial para el poder burocrático. Para creer en la legalidad de las instituciones se necesita una cierta imagen de cómo debe ser la ley, una ley ejemplar, usando la expresión de Arendt. No es sorprendente entonces descubrir que incluso la ley siempre ha tenido su política de imágenes (Douzinas y Nead, 1999).

Si lo imaginal es esencial para lo político, lo es con todas las ambivalencias que habían sido señaladas tiempo atrás sobre la imaginación. Lo imaginal es radical, pues puede hacer presente lo que está ausente en el doble sentido de crear algo nuevo, pero también de negar los hechos. La creación de imágenes es esencial para nuestra capacidad de acción, para comenzar algo nuevo en el mundo, pero también para nuestra habilidad para mentir. En ambos casos, se niega lo que está dado: en el primer caso, al crear algo nuevo, en el segundo al ocultarlo.

De ahí la necesidad de repensar lo imaginal en conexión con el proyecto de autonomía. Es en nuestra capacidad radical de cuestionar nuestras propias imá- 
genes donde reposa la posibilidad de crítica. Nadie señala mejor este punto que Castoriadis. Guiado por su propia lectura de la historia de la polis ateniense, lleva el argumento tan lejos como para postular una distinción entre el concepto de lo político y de la política. Mientras "lo político" denota la política como usualmente la entendemos (lo que Castoriadis denomina el poder explícito), la política, tal como ha sido inventada por los griegos, equivale a la puesta en cuestión explícita de las instituciones establecidas de la sociedad (Castoriadis, 1991: 159). No por azar él atribuye a los griegos el descubrimiento tanto de la política como de la filosofía: el pensamiento griego equivale a poner en tela de juicio las instituciones más importantes de la sociedad, las representaciones y normas de la tribu y la noción misma de verdad.

Si los griegos han inventado la filosofía y la política en el sentido de Castoriadis, es al menos, discutible. ${ }^{27}$ Pero incluso si lo hicieron, deberíamos llamarla más bien política democrática. El hecho de que Castoriadis hable de "verdadera política" o "política propiamente concebida" (Castoriadis, 1991: 160), que tenga la necesidad de agregar esas dos pequeñas palabras, "verdadera" y "propiamente", es la señal de que nos está tratando de persuadir de algo que va contra nuestro sentido común. Contrariamente a Castoriadis, yo pienso que nos deberíamos permitir violar la máxima nomina non sunt multiplicanda praeter necessitatem, si es necesario. En este caso, no obstante, hay un nombre para lo que Castoriadis llama "verdadera política", y éste es democracia. Permítannos, por tanto, atenernos a nuestra anterior (y más común) definición de política.

\section{(3) Transformaciones contemporáneas.}

Veamos ahora cómo el nexo entre lo político y lo imaginal cambia en las condiciones contemporáneas. Por una parte, la política contemporánea está abrumada por lo imaginal. Depende de imágenes, no sólo porque las imágenes median nuestro ser en el mundo y son, por lo tanto, cruciales para cualquier especie de comunicación y la comunicación política no es la excepción. Parece haber algo más, una suerte de hipertrofia de lo imaginal, en primer lugar debido a la difusión masiva de los medios. Si uno reflexiona sobre lo que la política solía ser antes de que el flujo de imágenes comience a entrar en nuestros hogares a través de la televisión, está claro que hay un cambio enorme en la naturaleza misma de la política. Nuestra experiencia política se ha tornado inconcebible por fuera del continuo flujo de imágenes que aparece en la pantalla. Las imágenes no son sólo lo que media nuestro hacer político; se han convertido en un fin en sí mismas, lo que pone en riesgo el hacer político en nuestro lugar. Sólo debemos pensar en el llamado mass-marketing de la política y en qué devino la democracia en la era de las imágenes manufacturadas en escala masiva (Newman, 1999). Como observa Meyer, independientemente del impacto real de los medios en la mente de las personas, el hecho es que los políticos se comportan como si las imágenes transmitidas por los medios fueran la realidad misma. Ninguna política pública, ninguna decisión, se toma sin primero, y ante todo, considerar como afectará su imagen en los medios (Meyer, 2002). 
Por otra parte, la política parece carecer de imaginación en el sentido de la capacidad de cuestionar lo dado. En una época en la cual la política se ve reducida a la gobernanza, a la simple administración dentro de un consenso general neoliberal, no hay espacio para imaginar cosas de forma diferente. ${ }^{28}$ Esta aparente paradoja es, de hecho, el resultado de la hipertrofia del lado más pasivo de la imaginación, que sucede a expensas de su lado más activo. Nos encontramos tan saturados de imágenes que se torna cada vez más difícil crear nuevas. Esto es consecuencia de un cambio tanto en la cantidad como en la calidad de las imágenes producidas en la época global. Con respecto a lo primero, no podemos dejar de notar un aumento decisivo en la cantidad de imágenes que entran a nuestras vidas. En particular, la cantidad de imágenes producidas por los medios ha alcanzado una proporción tal como para determinar también un cambio cualitativo: las imágenes se han convertido en un fin en sí mismo.

Más allá de que este proceso dinámico tiene un gran potencial democrático, ya que todos pueden intervenir en una imagen virtual, también habilita nuevos y terroríficos escenarios, porque no poseemos un criterio seguro que determine la autenticidad de dichas imágenes. Todo vale, incluso información falsa, siempre que capte la atención de la audiencia. Cuando lo que nos vincula es el deseo de ser notado, se nos invita a renunciar a la verdad y la realidad como los criterios fundamentales para decidir qué importa en la política y en la vida cotidiana.

Es sólo en este contexto de transformación profunda en la fenomenología de lo imaginal que podemos comprender fenómenos como el Trumpismo. Éste no es una mera consecuencia de la manipulación de nuestras capacidades para imaginar: el Trumpismo es posible, en primer lugar, porque se alimenta de estas transformaciones, que conscientemente, a su vez, busca afectar. En otras palabras, necesitamos entender por qué las personas estaban preparadas para intercambiar "noticias reales" por "noticias falsas" para comprender por qué la más profesional de las políticas que uno puede encontrar perdió las elecciones presidenciales con el menos profesional de su generación, quien ahora se sienta en la Casa Blanca.

Muchos autores, por ejemplo, han notado la función ritual de las elecciones. En virtud de su mera repetición, las elecciones refuerzan un cierto modelo de sociedad al proveerla de una continuidad visible. Pero, hoy en día, la cantidad de imágenes que acompañan las elecciones en la mayoría de los países occidentales se ha convertido en tal que el espectáculo prevalece completamente sobre el contenido. Es la ley de oro de la audiencia la que hace el trabajo: sólo aquellas imágenes que pueden captar la atención de la gente son seleccionadas. De ahí, la prevalencia del registro del espectáculo. Sin embargo, la batalla que se pone en el escenario de nuestras pantallas en ocasión de las elecciones, de hecho, esconde que ninguna batalla real está teniendo lugar, porque el enfrentamiento real no es entre los candidatos oficiales (que generalmente tienen programas similares), sino fuera de la pantalla. La lucha real es entre las opciones políticas que son admitidas y aquellas que quedan afuera. La distancia decisiva no se da entre candidatos, sino entre aquellos que tienen un papel en el espectáculo y aquellos que quedan fuera de él. ${ }^{29}$ 
En segundo lugar, también ha ocurrido un cambio cualitativo intrínseco en la naturaleza de las imágenes, una transformación que probablemente afecte profundamente el vínculo entre lo político y lo imaginal. Detrás de la revolución virtual, hay de hecho un cambio profundo en la naturaleza de las imágenes: no es sólo que las imágenes se han convertido en producto, las cuales, por lo tanto, se encuentran sujetas a la ley y tratamiento de todos los otros productos, sino que ahora también son maleables de una manera como nunca antes ha sucedido. Las imágenes no son sólo reproducibles en serie, sino que también son modificables hasta el punto en que pueden ser totalmente falsificables. En otras palabras, las imágenes han perdido completamente su vínculo con el ahora y aquí.

Una manera de ilustrar este punto es a partir de las reflexiones de Benjamin sobre la obra de arte en la época de su reproductibilidad técnica. Benjamin comienza con su observación de que, como consecuencia de su reproductibilidad (principalmente debido al cine y a la fotografía), las obras de arte han perdido su "aura". El aura es definido como "un extraño tejido de tiempo y espacio: la manifestación irrepetible de una lejanía (por cercana que pueda estar)" (Benjamin, 2002: 1045). ${ }^{30}$ Las imágenes artísticas han perdido su ser hic et nunc, aquí y ahora. Una pieza de música puede ser repetida en diferentes espacios y tiempos, de una forma sustancialmente idéntica, de manera que podemos decir que es precisamente ese concierto ejecutado por $\mathrm{X}$ e $\mathrm{Y}$ en el momento $\mathrm{Z}$, y no otro, siendo al mismo tiempo original y copia. De forma similar, una fotografía puede ser reproducida ad infinitum sin que sea posible de distinguir entre el original y las copias.

Con el advenimiento de las imágenes virtuales, hemos alcanzado un nivel adicional. Se puede argumentar que la fotografía y el cine aún mantenían una conexión con el hic et nunc. Una foto necesitaba ser tomada antes de ser reproducida, del mismo modo que una película necesitaba ser filmada en primer lugar. Incluso si ambas pudieran ser cortadas y ensambladas de forma diferente en diferentes tiempos, todavía poseían su forma original aquí y ahora, el momento en que fue sacada, filmada, creada. Todo esto es superado por la virtualidad. En una imagen virtual no hay hic et nunc y, en consecuencia, tampoco hay autenticidad que deba ser preservada, ni ningún original que nos oriente. Las imágenes virtuales no son objetos que pueden ser creados de una vez, sino procesos en curso. No hay una creación original, sino un proceso de conservación perpetua.

Uno de los problemas vinculado con esta transformación es el hecho de que las imágenes aún tienden a presentarse a ellas mismas como portadoras de un hic et nunc. Muchas de las patologías de lo imaginal de nuestro tiempo se relaciona con el hecho de que no existe una manera fácil de determinar el contexto de realidad de las imágenes. Aun así, hay también un potencial de nuevas formas de democratización en todo esto. Todos pueden potencialmente modificar una imagen virtual. Si un film necesitaba un equipo costoso para ser filmado, ahora un teléfono celular parece ser suficiente.

Tal vez sea demasiado pronto para comprender completamente la implicancia de esta transformación. Existen, sin embargo, signos que parecen apuntar a una dirección muy diferente de la tomada en el momento de Benjamin. Al comentar 
sobre las posibles consecuencias positivas de la transformación que presenció, Benjamin observó que la tecnología de reproducción separa el objeto reproducido de la esfera de la tradición: al replicar la obra muchas veces, sustituye una presencia masiva en el lugar de una presencia irrepetible. En su visión, el resultado de este proceso debería ser la ruptura de cada forma de tradición. El razonamiento de Benjamin es bastante claro: si la tradición depende de la autenticidad del objeto y la reproducción en masa destruye esa autenticidad, entonces también debe destruir la tradición.

Él pensaba que esto se tornaba más evidente en las películas. Su impacto social, particularmente en su forma más positiva, tenía un lado catártico, destructivo, a saber: "la liquidación del valor de la tradición en la herencia cultural" (Benjamin, 2002: 104). ${ }^{31} \mathrm{Al}$ comentar sobre el posible lugar para tal liquidación, observa: "Este fenómeno es sobre todo perceptible en las grandes películas históricas. Es éste un terreno en el que constantemente toma posiciones. Y cuando Abel Gance proclamó fervientemente en 1927: 'Shakespeare, Rembrandt, Beethoven, harán cine... Todas las leyendas, toda la mitología y todos los mitos, todos los fundadores de religiones y todas las religiones incluso... esperan a sus resurrecciones de celuloide, y los héroes se apelotonan, para entrar, ante nuestras puertas', estaba invitando a los lectores, sin saberlo, a ser testigos de una liquidación general" (Benjamin, 2002: 104). ${ }^{32}$

El tono sarcástico de este pasaje muestra cuán seguro estaba Benjamin sobre su predicción. Él escribió estas palabras entre fines de diciembre de 1935 y comienzos de febrero de 1936. Casi un siglo después, podemos decir que estaba completamente equivocado, o que, al menos, el desarrollo tecnológico que ha seguido tornó anticuado su análisis. De hecho, no sólo hemos tenido genios como Beethoven y Rembrandt haciendo películas, sino que, además, asistimos a una resurrección de todo tipo de mitos y religiones en y a través de lo imaginal. Vivimos en una época en donde los mitos, como el mito nacionalista, e incluso el del choque de civilizaciones, proliferan en los medios (Bottici, 2007). Del mismo modo, somos testigos de una nueva politización de la religión, que va de la mano con su mediatización (Bottici, 2009). Tanto los mitos como la religión han, para decirlo de alguna manera, sido resucitados. La única diferencia es que es una resurrección virtual, no de celuloide.

Para concluir, una teoría de lo imaginal puede ayudarnos a superar el impasse de la oposición entre teorías de la imaginación como una facultad individual y la teoría del imaginario como un contexto social. Como tal, es también la herramienta más apta para capturar la naturaleza del vínculo conceptual entre la política y nuestra capacidad de producir imágenes. Esta transformación imaginal también explica la paradoja de la cual partimos, un mundo político plagado de imágenes pero desprovisto de imaginación. La razón es que estamos saturados por el diluvio de imágenes, y nos tornamos aún más cínicos por su creciente espectacularización y virtualización, tenemos más dificultades para crear imágenes radicalmente alternativas de nuestra vida política presente y futura. Es en este espacio imaginal en el que proliferan los sentimientos de los llamados a los revivals nacionalismos. Pero 
también es en este espacio que necesitamos operar si deseamos crear alternativas para el futuro.

\section{Referencias}

1. La traducción de este texto fue realizada por el Dr. Gastón Souroujon, investigador del Consejo Nacional de Investigaciones Científicas y Técnicas y profesor de la Universidad Nacional de Rosario y la Universidad Nacional del Litoral, Argentina.

2. Para la genealogía del concepto de imaginación ver Cocking 1991, Engell 1981, Ferraris 1996, Fleury 2006, Friese 2001, Maguire 2006, Robinson and Rundell 1994, Vattimo 1999 b.

3. Sobre la phantasia en la filosofía griega ver Cocking 1991, Ferraris 1996, Watson 1988.

4. "Commonly exceeds the measure of nature, joining at pleasure things which in nature would never have come together, and introducing things which in nature would never have come to pass." Las citas textuales en su idioma original se expondrán en la nota a pie. En el cuerpo del texto sólo dejaremos las traducciones para aportar a una lectura más ágil. [Nota del traductor].

5. "Full of natural mistakes, which cannot be eliminated without divine grace." [N. del T.]

6. Maguire critica esta interpretación diciendo que Pascal tiene una visión más matizada de la imaginación (Maguire 2006: 17-59). Aun así, es muy difícil de negar que lo que emerge de este fragmento no es una visión negativa de la imaginación. Entre los que apoyan la lectura de Pascal como crítico de la imaginación ver Robinson and Rundell (1994: 120) y Cocking (1994: 265).

7. Para una reconstrucción detallada del quiebre semántico ver Cocking (1991), Ferraris (1996), Friese (2001), Vattimo (1999b).

8. En este punto ver Cocking (1991), Engell (1981). Novalis, por ejemplo, observa en la imaginación un poder que puede liberar de los sentidos y la comprensión: mientras éstos son de alguna manera mecánicos, la imaginación es una fuente de libertad. Como lo expresa abiertamente: "la imaginación es el sentido maravilloso que puede reemplazar todos los sentidos para nosotros- y que se sitúa bajo el poder de nuestra voluntad. Los sentidos orientados hacia el exterior se presentan como gobernados completamente por leyes mecánicas, en contraste la imaginación no se encuentra atada evidentemente a la presencia y el tacto de los estímulos externos" (Novalis 1977, II: 650). El arte es el dominio creado por la libertad de la imaginación, puede reunir aquello que ha sido separado por la ilustración.

9. He dedicado de manera extensa a esta crítica del romanticismo en Bottici (2007: 62-80).

10. Se puede observar, por ejemplo, Freud (1950), Kerényi and Jung (1963), Lévi-Strauss (1990).

11. De hecho, como he argumentado, Wittgenstein es muy ambiguo con el concepto de forma de vida (Bottici, 2007: 94-7).

12. Desde Francia, la intuición fenomenológica de Husserl del rol de la imaginación ha sido desarrollada por Sartre. Sin embargo, en los dos escritos de Sartre sobre el tópico permanece atado al concepto de imaginación como una facultad que representa lo que no existe, lo cual como veremos, es una muy limitada visión de la imaginación (Sartre, 1936, Sartre, 1940).

13. En relación con el tratamiento de Kant en torno al concepto de imaginación ver Arnason (1994), Engell (1981), Rundell (1994).

14. En torno a la importancia de la noción de "ejemplo" ver Ferrara (2008). Ferrara, sin embargo, critica la analogía de Arendt entre ejemplo y esquema cognitivo.

15. "This can be conceived of as a Platonic idea or Kantian schema... One more possibility is left, and this enters into judgements that are not cognitions: one may encounter or think of some table that one judges to be the best possible table and take this table as the example of how tables actually should be: the exemplary table ("example" comes from eximere, "to single out some particular"). This exemplar is and remains a particular that in its very particularity reveals the generality that otherwise could not be defined. Courage is like Achilles. Etc" [N. del T.].

16. De hecho, Habermas no se encuentra en una mejor situación. Castoriadis comienza con el aislamiento monádico y luego el problema comienza al establecer cómo la comunicación es posible. Habermas comienza con el hecho de la comunicación, pero entonces el problema es cómo relacionar esto con el inconsciente. Para este punto ver Whitebook (1989). 
17. No hay espacio aquí para un mayor desarrollo de este punto. Sólo observar que la visión del ser humano como un ser dependiente deriva del concepto Mangelwesen de Gehlen: somos seres dependientes porque somos seres deficientes, siempre incompletos e insuficientes para nosotros (Gehlen, 1997).

18. La razón porque la imaginación llegó a estar asociada con la idea de lo ficticio es que puede ser creada ex nihilo -no in nihilo or cum nihilo. La lógica de conjunto occidental, la cual se basa en el supuesto de la identidad ex nihilo nihil, no puede, como consecuencia, sino concebir la imaginación como esencialmente no existente. A esta lógica, que no puede explicar el hecho de que cuando " $\mathrm{x}=\mathrm{x}$ " es siempre " $\mathrm{x}=$ noX", Castoriadis contrapone la lógica de los magmas. El concepto de magmas apunta al hecho de que las significaciones no son "entes determinados" sino una red de referencias (faisceaux de renvois). Estas siempre son determinables, pero nunca completamente determinadas (Castoriadis, 1987: 221).

19. Basta con pensar que durante el medioevo la palabra realitas significaba "perfección”, de esta manera el ser más real era Dios y lo menos real nuestras percepciones sensoriales que nunca eran perfectas, mientras que en la época moderna el término asumió el sentido opuesto. He reconstruido este pasaje en Bottici (2007).

20. El término ha sido recuperado por Hilman en el contexto de su proyecto de una psicología junguiana renovada, y en consecuencia con un significado ligeramente diferente (Hillman, 1972), y más recientemente por Fleury (2006), quien se mantiene cerca de los textos de Corbin.

21. Utilizo aquí el vocablo político como un adjetivo de la política. Más adelante clarificaré cómo esto se relaciona con el uso que le da Castoriadis.

22. Para una reconstrucción de este concepto de política que deriva del término politikos de la antigua Grecia, ver Bobbio (1990: 800).

23. La referencia aquí es evidentemente a Imagined Communities de Anderson (1991).

24. "an enlarged community is the condition sine qua non of right judgement; one's community sense makes it possible to enlarge one's mentality.... Private conditions condition us; imagination and reflection enable us to liberate ourselves from them and to attain that relative impartiality that is the specific virtue of judgement" [N. del T.].

25. Para esta definición ver Weber (1978, I, § 17, IV §1, 2).

26. "beneath the monopoly of legitimate violence lies the monopoly of the valid signification. The throne of the Lord of signification stands above the throne of the Lord of violence. The voice of the arms can only begin to be heard amid the crash of the collapsing edifice of institutions. And for violence to manifest itself effectively, the word - the injunctions of the existing power - has to keep its magic over the 'group of armed men' (Engels)" [N. del T.].

27. He argumentado en otro lado que la misma idea de que los griegos han inventado la filosofía es bastante problemática (Bottici, 2007: 20-43).

28. El término gobernanza fue acuñado en los ochenta para ilustrar la política del Banco Mundial en un contexto jurídico que le niega a este organismo el derecho de ejercer funciones de gobierno. A partir de allí, gobernanza se convirtió en un sinónimo de una manera de hacer política la cual no implicaba gobierno, y por lo tanto, a menudo equivale a una mera técnica (Bottici, 2006).

29. La razón por la cual a menudo las encuestas sobre el rol de los medios en las elecciones no logran captar su impacto real se debe a que, en general, simplemente evalúan en qué medida los medios han influido en las preferencias de uno u otro candidato oficial. De hecho, el poder de los medios comienza antes, en hacer cierta opción política posible o no.

30. "a strange tissue of space and time: the unique apparition of a distance, however near it may be" [N. del T.].

31. "the liquidation of the value of tradition in the cultural heritage" [N. del T].

32. "Shakespeare, Rembrandt, Beethoven will make films....All legends, all mythologies, and all myths, all founders of religions, indeed, all religions,....attend their celluloid resurrections, and the heroes are pressing at the gates" he was inviting the reader, no doubt unawares, to witness a comprehensive liquidation" [N. del T]. 


\section{Bibliografía}

Anderson, B. (1991). Imagined Communities. Reflections on the Spread of Nationalism. London: Verso.

Arendt, H. (1972). "Lying in Politics". In Crises of the Republic. New York: Harvest/HBJ.

Arendt, H. (1982). Lectures on Kant's Political Philosophy. Brighton: Harvester.

Arnason, J. P. (1994). "Reason, imagination, interpretation". G. Robinson and J. Rundell (eds), Rethinking Imagination: Culture and Creativity. London: Routledge, 155-70.

Aristotle (1964). On the Soul. Parva Naturalia. On Breath (eng. trans. by W.S. Hett) Loeb Classical Library. Cambridge: Harvard University Press.

Bacon, F. (1963). De dignitate et augmentis scientiarum. In The Works of Francis Bacon. Stuttgart: Fromann, Vol. I, 415-838.

Bacon, F. (1986). "Of the Dignity and Advancement of Learning”. In The Works of Francis Bacon. Stuttgart: Fromann, Vol. IV, 275-498.

Benjamin, W. (2002). "The Work of Art in the Age of Its Technological Reproducibility". In Selected Writings. Volume 3. 1935-1938. Cambridge: Belknap Press of Harvard University Press.

Bottici, C. (2006). "War and Conflict in a Globalising World: Governance or Empire?" Romanian Journal of Political Science, 6, 1: 3-23.

Bottici, C. (2007). Philosophy of Political Myth. Cambridge: Cambridge University Press.

Bottici, C. (2009). "The Politics of Imagination and the Public Role of Religion". Philosophy and Social Criticism, $\mathrm{N}^{\circ} 35,8: 1-22$.

Busino, G. et alii (eds) (1989). Autonomie et autotransformation de la société. La philosophie militante de Cornelius Castoriadis. Genève : Libraire Droz.

Castoriadis, C. (1987). The Imaginary Institution of Society. Cambridge: Polity Press.

Castoriadis, C. (1982). "Institution de la société et religion". In Domaines de l'homme. Le carrefour du labyrinthe. Paris: Seuil, 455-481.

Castoriadis, C. (1986). Domaines de l'homme. Le carrefour du labyrinthe. Paris: Seuil.

Castoriadis, C. (1991). "Power, Politics, Autonomy". In Philosophy, Politics, Autonomy - Essays in political philosophy. Oxford: Oxford University Press, 143-175.

Castoriadis, C. (1994). "Radical Imagination and the Social Instituting Imaginary". In The Castoriadis Reader. Oxford: Blackwell, 319-338.

Cocking, J. M. (1991). Imagination: A Study in the History of Ideas. London: Routledge.

Corbin, H. (1979). Corp spirituel et terre céleste. Paris: Buchet-Chastel.

Coulter, J. (1999). "Discourse and Mind". Human Studies, 22: 163-81.

Douzinas, C. and Nead, L. (1999). Law and Image. Chicago: The University of Chicago Press.

Engell, J. (1981). The Creative Imagination. Enlightenment to Romanticism. Cambridge: Harvard University Press.

Ferraris, M. (1996). L'immaginazione. Bologna: Il Mulino.

Fleury, C (ed). (2006). Imagination, imaginaire, imaginal. Paris: PUF.

Freud, S. (1950). Totem and Taboo. New York: Norton.

Friese, H. (2001). "Imagination: History of the concept". In N. J. Smelser and P.B. Baltes (eds) International Encyclopedia of The Social \& Behavioural Sciences. Amsterdam: Elsevier, vol.11, 71977201.

Gehlen, A. (1988). Man, His Nature and Place in The World. New York: Columbia University Press. Habermas, J. (1987). The Philosophical Discourse of Modernity. Twelve Lectures. Cambridge: Polity Press.

Hillman, J. (1972). The Myth of the Analysis. Evanston: Northwestern University Press.

Kant, I. (1998). Critique of Pure Reason, eng. trans. by P. Guyer and A.W. Wood. In The Cambridge Edition of the Works of Immanuel Kant. Cambridge: Cambridge University Press.

Kant, I. (2000). Critique of the Power of Judgment, eng. trans. by P. Guyer and E. Matthews. In The Cambridge Edition of the Works of Immanuel, Kant. Cambridge: Cambridge University Press.

Kerényi, K. and Jung, C.G. (1963). Essays on a Science of Mythology. Princeton: Princeton University Press. 
Lévi-Strauss, C. (1990). The Naked Man. Chicago: University of Chicago Press.

Maguire, M. (2006). The Conversion of Imagination. From Pascal through Rousseau to Tocqueville. Cambridge Mass: Harvard University Press.

Meyer, T. (2002). Media Democracy: How the Media Colonize Politics. Oxford: Polity Press.

Newman, B. (1999). The Mass Marketing of Politics. Democracy in an Age of Manufactured Images. London: Sage.

Novalis. (1977). Schriften, in Die Werke Friedrich von Hardenbergs. In P. Kluckhohn and R. Samuel (eds). Stuttgart: Kohlhammer.

Pascal, B. (1963). Ouvres complètes. Paris: Seuil.

Robinson, G. and Rundell, J. (eds) (1994). Rethinking Imagination: Culture and Creativity. London: Routledge.

Rundell, J. (1994a). "Introduction" in Robinson, G. and Rundell, J. (eds) (1994) Rethinking Imagination: Culture and Creativity, pp. 1-11. London: Routledge, 1-11.

Rundell, J. (1994b). "Creativity and judgment: Kant on reason and imagination”. In G. Robinson, and J. Rundell, Rethinking Imagination: Culture and Creativity. London: Routledge, 87-117.

Sartre, J-P. (1936). L'imagination, Paris: PUF. Sartre, J-P.

Sartre, J-P. (1940). L'imaginaire, Paris: Gallimard.

Simpson, J.A., Weiner, E.S.C. (eds.) (1989). The Oxford English Dictionary. Oxford: Clarendon Press.

Vattimo, G. (1999a). "Estetica”. In Enciclopedia di filosofia, pp. 340-345. Milano: Garzanti.

Vattimo, G. (1999b). "Immaginazione”. In Enciclopedia di filosofia. Milano: Garzanti, 528-530.

Von Savigny, E. (1991). “Common Behavior of Many A Kind”. In R. L. Arrington and H. J. Glock (eds), Wittgenstein's Philosophical Investigations: Text and Context. London: Routledge, 105-119. Watson, G. (1988). Phantasia in Classical Thought. Galway: Galway University Press.

Weber, M. (1978). Economy and Society, eng. trans. by Fischoff, E. et alii (eds). Berkeley: University of California Press.

Whitebook, J. (1989). "Intersubjectivity and the Monadic Core of the Psyche: Habermas and Castoriadis on the Unconscious". In G. Busino et alii (eds), Autonomie et autotransformation de la société. La philosophie militante de Cornelius Castoriadis. Genève: Libraire Droz, 225-245.

Recibido: 20/03/2018. Aceptado: 15/05/2018.

Chiara Bottici, "De la política de la imaginación a la política Imaginal". Revista Temas y Debates. ISSN 1666-0714, año 22, número 36, julio-diciembre 2018, pp. 21-39. 